\title{
Effect of Ageing Temperature on the Mechanical Properties of Al-6Si-0.5Mg Cast Alloys with Cu Additions Treated by T6 Heat Treatment
}

\author{
A. Hossain*, A. S. W. Kurny \\ Bangladesh University of Engineering and Technology, Department of Materials and Metallurgical Engineering, Dhaka 1000, Bangladesh \\ *Corresponding Author: ah_buetmmesgfl@live.com
}

Copyright (C) 2013 Horizon Research Publishing All rights reserved.

\begin{abstract}
Effect of artificial ageing temperature on the mechanical properties of $\mathrm{Al}-6 \mathrm{Si}-0.5 \mathrm{Mg}$ alloy containing 0.5 - $4 \mathrm{wt} \% \mathrm{Cu}$ was studied. The solution treated alloys containing different amounts of $\mathrm{Cu}$ were aged isochronally for 1 hour at temperatures up to $300^{\circ} \mathrm{C}$. The precipitation stages during ageing were monitored by hardness measurements. Tensile and impact properties were determined by standard tests. During artificial ageing, the yield and ultimate tensile strengths were found to increase with ageing temperature; the maximum being attained at peak aged condition. Ductility and impact toughness of the alloys, on the other hand decreased with ageing temperature reaching the minimum at the highest hardness. The addition of $\mathrm{Cu}$ resulted in an increase in hardness and tensile strength and substantial reduction of ductility and fracture toughness.
\end{abstract}

Keywords Al-6Si-0.5Mg Alloy, Age hardening, Tensile properties, Fracture toughness, SEM

\section{Introduction}

Due to high strength-to weight ratio, besides other desirable properties like appearance, high corrosion resistance, high electrical and thermal conductivities and ease of fabrication, aluminum and its alloys are used in a wide range of industrial applications, particularly in aircraft and space vehicles, construction and building, containers and packaging and in electrical transmission lines [1]. Controlled thermo mechanical treatments can induce considerable improvements in yield strength and hardness of age hardenable Al-alloys. Micro mechanisms governing fracture characteristics of such alloys depend on coherency and distribution of precipitates, grain size and shape, grain boundary precipitates and presence of other second phase particles that result from impurities. The unstable fast fracture, even if it is ductile, becomes frequent because the strengthening lowers the level of toughness, and this becomes a problem with large scale structures. Since the fracture of many engineering components is promoted under dynamic conditions, there is a need to understand the fracture behaviour of materials under dynamic loads. Moreover, fracture characteristics under the impact load seem to become important, because the application to transportation vehicles is likely to increase [2].

Precipitation hardening is the most common method to increase the strength of the heat treatable aluminum alloys. This method includes a solution heat treatment at high temperature to maximize solubility, followed by rapid cooling or quenching in water to obtain a solid solution super saturated with the solute elements ( $\mathrm{Mg}$ and $\mathrm{Si}$ ), followed by aging heat treatment (which may include either natural aging or artificial aging) to produce finely dispersed precipitates. Solution heat treatment is designed to maximize the solubility of solute elements which are precipitated during subsequent aging. It is most effective when carried out at temperatures near the solidus, where maximum solubility exists and diffusion rates are rapid.

When a heat-treatable A356 aluminum alloy undergoes precipitation hardening (age-hardening), fine precipitants will dissolve completely in saturated matrix to achieve high strength in material [3]. The super-saturated solid solution undergoes aging treatment; a large amount of small and uniformly distributed precipitants will appear thus the mechanical properties of the material can be improved. Uniform and delicate $\mathrm{Mg}_{2} \mathrm{Si}$ precipitants can be obtained in the matrix of a heat-treatable Al-Si-Mg casting part with T6 treatment (which involves solution treatment, quenching and artificial aging), leading to improvements in its tensile strength, elongation and toughness $[4,5]$. Therefore, during fracture mechanics tests; it may be advantageous to include Charpy impact tests so that empirical correlations between the various fracture parameters can be developed. Numerous studies have been undertaken on evolution of microstructure, tensile properties and fracture toughness of precipitation hardened Al-alloys [6-15].

The successive precipitation sequence in Al-Si alloys to 
which $\mathrm{Mg}$ has been added is $\left.\beta_{\mathrm{SSS}} \rightarrow \beta^{\prime \prime} \rightarrow \beta^{\prime} \rightarrow \beta\left(\mathrm{Mg}_{2} \mathrm{Si}\right)\right)$ and in $\mathrm{Al}-\mathrm{Si}-\mathrm{Mg}$ alloys with $\mathrm{Cu}$ addition is $\alpha_{\mathrm{SsS}} \rightarrow \theta^{\prime \prime} \rightarrow \theta^{\prime}$ $\rightarrow \theta\left(\mathrm{CuAl}_{2}\right)$ where; $\beta_{\mathrm{Sss}}$ and $\alpha_{\mathrm{SsS}}$ is the supersaturated solid solution. The complete precipitation sequence can only occur when the alloy is aged at temperatures below the GP zone solvus. The mechanism of the transformation sequence usually involves heterogeneous nucleation at the sites of earlier products, resulting in fine and uniform precipitate dispersions $[16,17]$.

The present work focuses on how the changes of artificial ageing temperature influence the mechanical properties of cast $\mathrm{Al}-6 \mathrm{Si}-0.5 \mathrm{Mg}$ alloys containing different amounts of $\mathrm{Cu}$.

\section{Materials and Methods}

Melting was carried out in a natural gas heating pot furnace under the suitable flux cover (degasser, borax etc.). Several heats were taken for developing base Aluminium-Silicon-Magnesium alloy,

Aluminium-Silicon-Magnesium alloy containing Copper at various levels. In the process of preparation of the alloys the commercially pure aluminium $(99.7 \%$ purity) was taken as the starting material. First the aluminium and aluminium-silicon master alloy melted in a clay-graphite crucible, Copper, in the form of sheet ( $99.98 \%$ purity), was then added by plunging. Magnesium ribbon ( $99.7 \%$ purity) was added into solution duly packed in an $\mathrm{Al}$ foil. The final temperature of the melt was always maintained at $900 \pm 15^{\circ} \mathrm{C}$ with the help of an electronic controller. Before casting, the melt was degassed with solid hexachloroethane $\left(\mathrm{C}_{2} \mathrm{H}_{6}\right)$ and homogenized by stirring at $690^{\circ} \mathrm{C}$. Casting was done in cast iron metal moulds measuring $15 \times 150 \times 300$ in millimetre and preheated to $200^{\circ} \mathrm{C}$. All the alloys were analysed by wet chemical and spectrochemical methods simultaneously. The chemical compositions of the alloys are given in Table 1 . The cast samples were first ground properly to remove the oxide layer from the surface. All the alloys were then homogenised for 24 hours at a temperature of $500^{\circ} \mathrm{C}$. The homogenised cast samples were solution treated at $540^{\circ} \mathrm{C}$ for 120 minutes in ice cooled salt-water solution.

Prior to artificial ageing, the solution treated samples were kept at room temperature for 1 day. Artificial ageing was conducted in an electrical furnace. All the samples (only slices) were isochronally aged at room temperature, 100, 150, $175,200,225,250,300,350$ and $400^{\circ} \mathrm{C}$ for 1 hour. Subsequently, the samples were taken out from the furnace and cooled in still air. The hardness of all the artificially aged samples was determined on a Rockwell hardness testing machine using the F scale with a dwell time of $15 \mathrm{~s}$. Hardness measurements were performed on polished slices measuring $20 \mathrm{~mm} \times 20 \mathrm{~mm} \times 8 \mathrm{~mm}$. An average of seven consistent readings was accepted as the representative hardness value of an alloy.

Sub-size standard tensile (ASTM E8 M-04) and impact test specimens $\left(10 \mathrm{~mm} \times 10 \mathrm{~mm} \times 55 \mathrm{~mm}\right.$ in size, a $45^{\circ} \mathrm{V}$ notch of $2 \mathrm{~mm}$ depth and $0.25 \mathrm{~mm}$ root radius) were prepared from the homogenised samples. The tensile and impact test specimens were subjected to solution treatment at $540^{\circ} \mathrm{C}$ for 2 hours and then artificially aged at room temperature, 150 , $200,225,250$ and $300^{\circ} \mathrm{C}$ for 1 hour. Tensile testing was carried out in an Instron testing machine at a strain rate of $10^{-3} / \mathrm{s}$ and the Charpy impact testing was performed using an impact testing machine (JB-500B). The averages of three consistent test results were accepted as the tensile and impact value for the corresponding sample. Fractographic observation of the selected fractured tensile sample was carried out in a Scanning Electron Microscope Inspect $^{\mathrm{TM}}$ S50 FEI Quanta).

Table 1. Chemical composition of the experimental alloys (wt \%)

\begin{tabular}{|c|c|c|c|c|}
\hline Alloy Name & $\mathrm{Si}$ & $\mathrm{Mg}$ & $\mathrm{Cu}$ & $\mathrm{Al}$ \\
\hline Alloy-1 & 5.902 & 0.461 & 0.007 & Bal. \\
\hline Alloy-2 & 6.033 & 0.517 & 0.558 & Bal. \\
\hline Alloy-3 & 6.105 & 0.555 & 1.185 & Bal. \\
\hline Alloy-4 & 5.801 & 0.497 & 1.980 & Bal. \\
\hline Alloy-5 & 5.884 & 0.532 & 3.800 & Bal. \\
\hline
\end{tabular}

Remarks:

Alloy 1: Al-6 wt $\%$ Si- $0.5 \mathrm{wt} \% \mathrm{Mg}$

Alloy 2: Al-6 wt $\%$ Si-0.5 wt $\% \mathrm{Mg}-0.5 \mathrm{wt} \% \mathrm{Cu}$

Alloy 3: Al-6 wt $\%$ Si-0.5 wt $\% \mathrm{Mg}-1 \mathrm{wt} \% \mathrm{Cu}$

Alloy 4: Al-6 wt $\%$ Si-0.5 wt $\% \mathrm{Mg}-2 \mathrm{wt} \% \mathrm{Cu}$

Alloy 5: Al-6 wt $\% \mathrm{Si}-0.5 \mathrm{wt} \% \mathrm{Mg}-4 \mathrm{wt} \% \mathrm{Cu}$

\section{Results and Discussion}

\subsection{Effect of Artificial Ageing Temperature on Hardness}

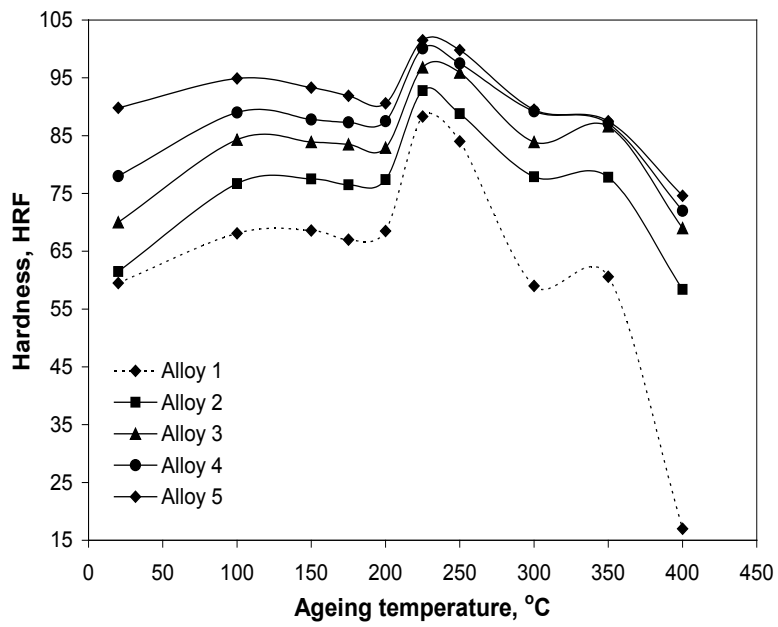

Figure 1. Variation of hardness of the alloys as a function of artificial ageing temperature isochronally aged for 1 hour. 
Fig.1 shows the isochronal aging behavior of the different alloys. For all alloys, the peak aging condition was attained by ageing for 1 hour at $225^{\circ} \mathrm{C}$. The hardness of the base alloy (alloy 1) was always found to be lower than the Cu-bearing alloys (alloys 2-5). The hardness decreased significantly with increasing aging temperature beyond $250^{\circ} \mathrm{C}$. The $\mathrm{Cu}$-bearing alloys, on the other hand, exhibited a stronger resistance to softening in comparison with the base alloy. Hardness in both as-quenched sample and in sample aged at $225^{\circ} \mathrm{C}$ increases strongly with increase of $\mathrm{Cu}$ content. The increase of hardness in as-quenched condition $\left(25^{\circ} \mathrm{C}\right)$ with increase of $\mathrm{Cu}$ content indicates that the solid-solution strengthening of the alloys is enhanced with increase of $\mathrm{Cu}$ content. Overageing decreases the hardness value of the alloys.

\subsection{Effect of Artificial Ageing Temperature on Yield Strength}

The variation in yield strength $(0.2 \%$ proof strength $)$ of the alloys 1-5 under various aging conditions is shown in Fig.2. Test values obtained at a strain rate of $10^{-3} \mathrm{~s}^{-1}$ were used to plot the graph. Fig. 2 shows that the yield strength of the alloys increases to a peak value at an aging temperature of $225^{\circ} \mathrm{C}$. Aging at temperatures beyond $225^{\circ} \mathrm{C}$ was found to lower the yield strength of the alloys. In the base alloy (Al-6Si- $0.5 \mathrm{Mg}$ alloy) the variation in yield strength with aging temperature is not very significant. When the alloys are aged at 150 to $225^{\circ} \mathrm{C}$, the yield strength increases with increasing copper content up to 2 wt. \% copper. With addition of copper beyond this level, a marginal fall in yield strength was observed. Further ageing $\left(250^{\circ} \mathrm{C}\right.$ and $\left.300^{\circ} \mathrm{C}\right)$ beyond the peak-aged condition, the yield strength of the alloys decreased due to overage.

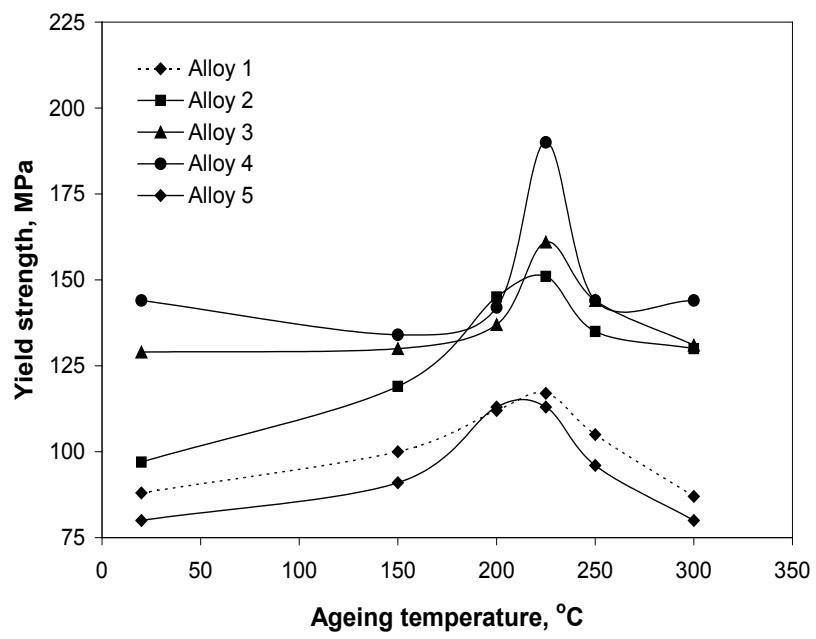

Figure 2. Variation of yield strength of the alloys as a function of artificial ageing temperature isochronally aged for 1 hour.

\subsection{Effect of Artificial Ageing Temperature on the Tensile Strength}

Fig.3 shows that the copper-containing alloys experience extra strengthening due to age-hardening effect and the maximum in tensile strength value is achieved by aging for one hour at a temperature of $225^{\circ} \mathrm{C}$. It is further observed that increasing ageing temperature up to $225^{\circ} \mathrm{C}$ increases the tensile strength of the alloys. Increase in copper content beyond $2 \mathrm{wt} \% \mathrm{Cu}$ causes a drop in the tensile strength value under all aging conditions.

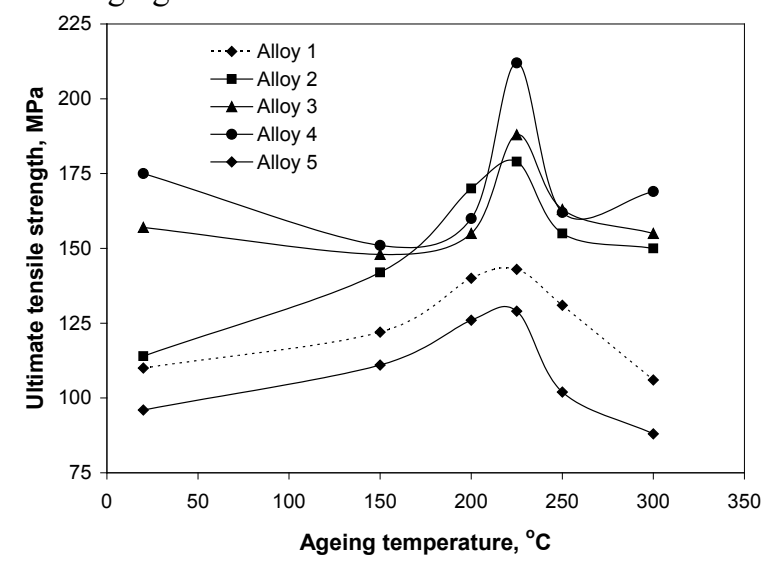

Figure 3. Variation of ultimate tensile strength of the alloys as a function of artificial ageing temperature isochronally aged for 1 hour.

\subsection{Effect of artificial ageing temperature on percent elongation}

Fig. 4 demonstrates the variation in percent-elongation with aging temperatures of alloys $1-5$. It can be seen that at the aging temperature for which strength is maximum $\left(225^{\circ} \mathrm{C}\right)$, the ductility values of the alloys (except alloys 1 and 2) pass through a minimum. The ductility of alloy 1 was found to be a minimum at $200^{\circ} \mathrm{C}$, and that of alloy 2 at $250^{\circ} \mathrm{C}$. The ductility value of the aged alloy 5 (containing $4 \mathrm{wt} \% \mathrm{Cu}$ ) was found to be less than all the other alloys for all aging conditions.

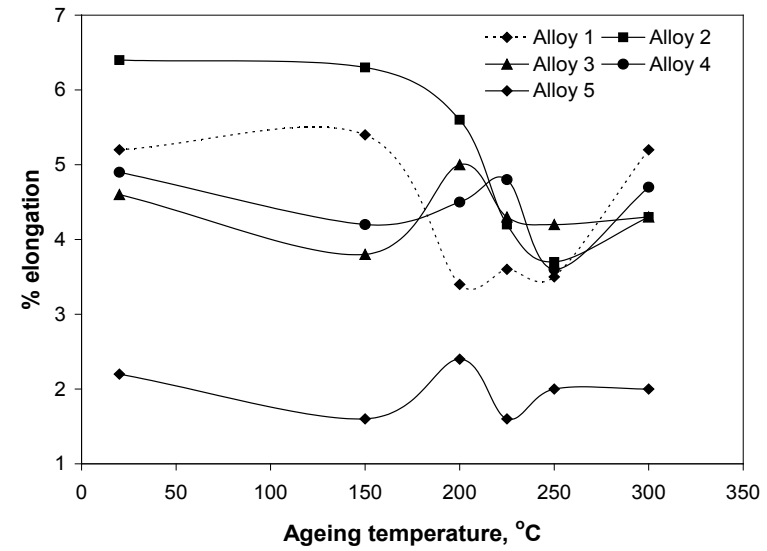

Figure 4. Variation of percent elongation of the alloys as a function of artificial ageing temperature isochronally aged for 1 hour.

\subsection{Effect of Artificial Ageing Temperature on Fracture Toughness}

Fig. 5 shows the energy absorbed during fracture as a 
function of artificial ageing temperature. Heat treatment, especially solution treatment and ageing, greatly influenced the capacity of absorbed energy. In the as-quenched condition, the alloys have shown higher toughness than in the peak-aged $\left(1 \mathrm{hr}\right.$ at $\left.225^{\circ} \mathrm{C}\right)$ condition. The toughness of the base alloy is higher than the $\mathrm{Cu}$-bearing alloys. As the ageing temperature increases from room temperature $\left(25^{\circ} \mathrm{C}\right)$ to $225^{\circ} \mathrm{C}$, the absorbed energy decreases for all the alloys. The decrease in absorbed energy is due to the brittleness caused by precipitation of intermediate phases. The maximum decrease in absorbed energy was observed in the peak aged condition. Further ageing from 225 to $300^{\circ} \mathrm{C}$ the absorbed energy increases slightly and this was due to overage.

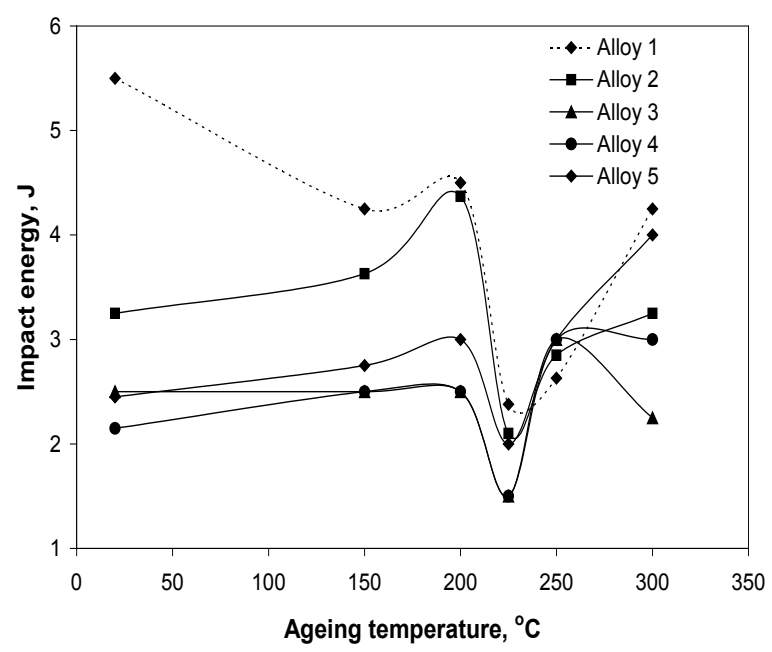

Figure 5. Variation of impact absorbed energy of the alloys as a function of artificial ageing temperature isochronally aged for 1 hour.

\subsection{Fracture Surface Analysis}

Treated specimens were more brittle and showed higher tensile strength than the specimens without $\mathrm{T} 6$ heat treatment. Fig. 6 shows the appearance of the fractured surface of the samples in the T6 treated condition. The figure shows large and small dimple structure and broken or cracked primary $\mathrm{Si}$ particles. This indicates that the fracture was ductile fracture in the $\mathrm{Al}$ matrix and brittle in the primary Si particles. It may thus be assumed that the fracture of the primary Si particles is responsible for the relatively low ductility of the T6 treated specimens. In fig. 6 the presence of microvoid (shrinkage porosity) on the fracture surface is shown. The void formed at the interfaces between the $\mathrm{Si}$ particles and $\mathrm{Al}$ matrix enhanced the crack propagation through their centre. On the fracture surface and in micro voids, the presence of secondary phase precipitates $\left(\mathrm{Al}_{2} \mathrm{Cu}, \mathrm{Mg}_{2} \mathrm{Si}\right)$ also contribute to mechanical properties by increasing the bonding of the matrix and reduced the ductility.

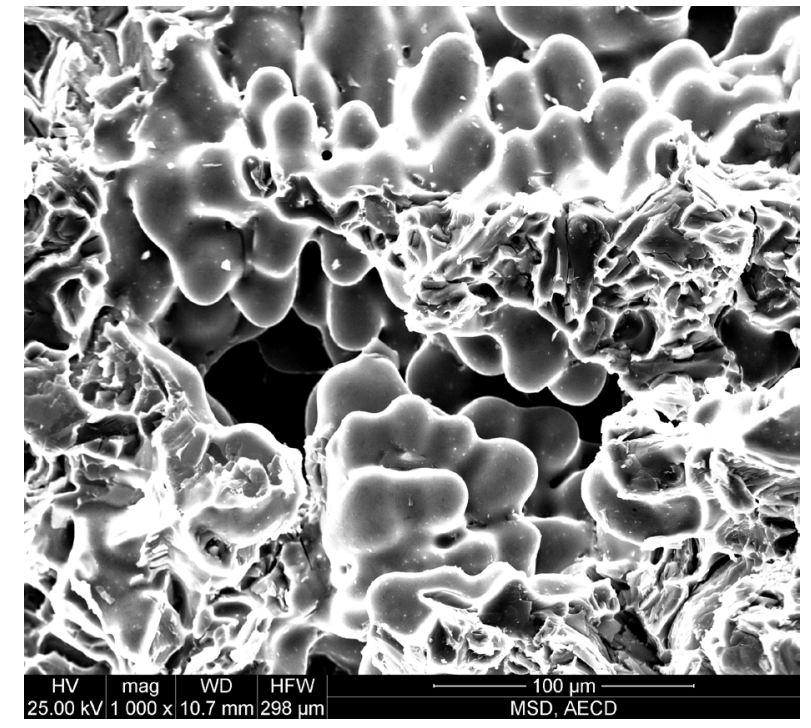

Figure 6. SEM fractograph of alloy 4 , aged at $225^{\circ} \mathrm{C}$ for 1 hour and tensile tested at strain rate of $10^{-3} \mathrm{~s}^{-1}$

\section{Conclusions}

Addition of $\mathrm{Cu}$ to $\mathrm{Al}-6 \mathrm{Si}-0.5 \mathrm{Mg}$ alloy decreases the age hardening rate. An increase in $\mathrm{Cu}$ content enhances the solid-solution strengthening of $\mathrm{Al}-6 \mathrm{Si}-0.5 \mathrm{Mg}$ alloys. The strong increase of maximum hardness during ageing with increase of $\mathrm{Cu}$ content is mainly the results of precipitation strengthening. Addition of $\mathrm{Cu}$ to the $\mathrm{Al}-6 \mathrm{Si}-0.5 \mathrm{Mg}$ cast alloy resulted in improved strength and reduced ductility. The Ageing temperatures have a great effect on the properties. The maximum strength is observed after ageing at $225^{\circ} \mathrm{C}$ for 1 hour (peakaged). The alloys with the lowest fracture toughness and ductility correspond to those that show the highest value of strength and hardness.

\section{REFERENCES}

[1] A. E. Al-Rawajfeh and S.M.A. Al Qawabah. Emirates Journal for Engineering Research, Vol.14, No.1, 47-52, 2009.

[2] T. Kobayashi. Mater. Sci. Eng. A Vol.286, 333-341, 2000.

[3] D. Apelian, S. Shivkumar, and G. Sigworth. American Foundry Society Transaction, Vol.97, 727-742, 1989.

[4] S. Shivkumar, C. Keller and D. Apelian. American Foundry Society Transaction, Vol.98, 905-911, 1990.

[5] R. Sinfield, and D. A. Harris. Journal of Australian Institute of Metals, Vol.20, No.1, 44-47, 1975.

[6] N. Ryum. Acta Metall, Vol.16, 327-332, 1968.

[7] I. Kovacs, J. Lendvai, T. Ungar, T. Turmezey, G. Groma. Acta Metall., Vol.25, 673- 680, 1977.

[8] G. G. Garrett, J. F. Knott. Metal. Trans., Vol.9, No.A, 1187-1201, 1978. 
[9] A. Melander, P. A. Persson. Acta Metall.,Vol.26, 267-278, 1978.

[10] T. S. Srivatsan. J Mater. Sci.,Vol. 274772-4781, , 1992.

[11] A. K. Mukhopadhyay, Q. B. Yang, S. R. Singh. Acta Metall. Mater.,Vol.42, 3083-3091, 1994.

[12] X. Z. Li, V. Hansen, J. Gjonnes, L. R. Wallenberg. Acta Mater., Vol.47, 2651-2659, 1999.

[13] S. P. Ringer, K. Hono, Mater. Charact., Vol.44,101-131, 2000.

[14] G. Waterloo, V. Hansen, J. Gjonnes, S. R. Skjervold. Mater. Sci. Eng. A, Vol.303, 226-233, 2001.

[15] D. Dumont, A. Deschamps, Y. Brechet. Mater. Sci. Eng. A, Vol.356, 326-336, 2003.

[16] S. P. Ringer, K. Hono, Mater. Charact.,Vol. 44, 101-131, 2000.

[17] D. Sun, X. Sun, D. O. Northwood, J. H. Sokolowski, Mater. Charact., Vol.36, 83-92, 1996.

[18] I. C. Barlow, W. M. Rainforth, H. Jones. Mater.Sci.,Vol.35,1 413-81,2000. 